\title{
Attainment Levels of Speaking Ability of Japanese Junior High School Students
}

\author{
Rie KOIZUMI \\ Doctoral Course, University of Tsukuba
}

This paper investigates (a) the applicability of North's (2000) language proficiency scale to junior high school (JHS) students in Japan, and (b) attainment levels on North's scale of JHS students as measured with a task-based interview test, which was analyzed using the multi-faceted Rasch measurement model (Linacre, 2003). The analysis of 171 students' utterances shows that (a) North's scale suits Japanese JHS students overall, and that (b) the attainment levels of speaking ability are the Smattering level for public third-year JHS students on average, and the Breakthrough or Waystage levels for public third-year JHS students with higher proficiency. When students at national JHSs are considered, the maximum level may be expanded to the Waystage Plus or above level. It is concluded that North's scale can be appropriately used in the Japanese educational context without modification and that the Tourist to Threshold levels may be realistic goals for JHS students in Japan.

\section{Introduction}

In "an Action Plan to Cultivate 'Japanese with English Abilities," the Ministry of Education, Culture, Sports, Science and Technology (MEXT, 2003) proposed goals of "English language abilities required for all Japanese nationals": Junior-high-school graduates "can conduct basic communication with regard to areas such as greetings, responses, or topics relating to daily life," while senior-high-school graduates "can conduct normal communication with regard to topics, for example, relating to daily life." The MEXT also established explicit exit criteria for average students: passing "the third level of the Society for Testing English Proficiency (STEP)" for junior high school (JHS) students and "the second level or the pre-second level of the ... STEP" for senior high school students.

While these attempts to clarify goals are beneficial, there seem to be two problems. ${ }^{1}$ First, the STEP evaluation standards used as the basis are rather simple (see Society for Testing English Proficiency Inc., 2001) and do not seem to be theoretically or empirically grounded. Second, it seems unclear whether the goals of "the third level" or "the second or pre-second level" of the STEP are appropriate because the MEXT does not present rationales for its plans. Niisato (2003), Erikawa (2004), and Nihon Gaikokugo Kyouiku Kaizen Kyougikai $(2003,2004)$ point out that there is a wide gap between the curriculum and the goals in the Action Plan. Since these goals are likely to be used for various purposes, such as curriculum development and program evaluation, the two issues above may have serious consequences and need to be addressed in detail. 
The first problem regarding the STEP evaluation standards can be tackled using two approaches. First, the STEP evaluation standards could be used after the modification or validation of level descriptors. Second, other existing scales with more detailed standards or descriptors could be (a) used as they are, (b) utilized after some modifications, or (c) created originally, according to the Japanese context of English language teaching. Although two approaches are possible, the first or second in the second approach (i.e., (a) and (b)) seem to work better in terms of quality and efficiency. In this study, North's (2000) language proficiency scale was selected for reasons explained in the next section, and was examined concerning suitability for the Japanese context.

As for the second problem of the appropriacy of goals presented in the Action Plan, the goals need to be realistic and to be determined based on present attainment levels obtained through empirical research. In addition, it may be necessary for the levels to be based on a proficiency scale with theoretical and empirical underpinnings. However, to the best of my knowledge, there are no such studies that have examined the current attainment levels of Japanese learners of English. Therefore, the current study aims to investigate attainment levels of Japanese JHS students, specifically levels of speaking ability, because the enhancement of speaking ability is emphasized (MEXT, 2003).

This paper first explains the selection criteria of North (2000) and then develops a speaking test that enables test users to assess speaking ability based on North's scale. While positive validity evidence of the test is explored and reported, attainment levels of speaking ability of Japanese JHS students are examined in order to set realistic goals for Japanese JHS students.

\section{North's Proficiency Scale}

A language proficiency scale is defined as "a scale for the description of language proficiency consisting of a series of constructed levels against which a language learner's performance is judged" (Davies et al., 1999, p. 153). Among many proficiency scales (North, 2000, 2002a), North's (2000) scale (see Table 1) is selected in the current research for the following three reasons. Firstly, it is more comprehensive, with clear descriptors, and it has theoretical and empirical underpinnings. It is based on 41 existing proficiency scales (North, 2002a), which include the English National Curriculum and the American Council on the Teaching of Foreign Languages (ACTFL) Proficiency Guidelines. Although the existing scales have suffered from some problems, for example, vagueness of the wording of descriptors and negative wording (North, 2000, 2002a), North (2000) has modified these problematic descriptors before incorporating them into his own scale. 
Table 1. North's Levels and Examples of Proficiency Descriptors

\begin{tabular}{|c|c|}
\hline Level & tor \\
\hline $\begin{array}{l}\text { Mastery [Proficient } \\
\text { User] }\end{array}$ & $\begin{array}{l}\text { Has a good command of idiomatic expression and } \\
\text { colloquialisms with awareness of connotative levels of } \\
\text { meaning. }\end{array}$ \\
\hline $\begin{array}{l}\text { Operational } \\
\text { cy } \\
\text { it User] }\end{array}$ & $\begin{array}{l}\text { Can express him/herself fluently and spontaneously, almost } \\
\text { effortlessly. Has a good ci)mmand of a broad lexical repertoire } \\
\text { allowing gaps to be readily overcome with circumlocutions. }\end{array}$ \\
\hline $\begin{array}{l}\text { Vantage } \quad \text { Plus } \\
\text { [Independent User] }\end{array}$ & $\begin{array}{l}\text { Can use the language fluently, accurately and effectively on a } \\
\text { wide range of general, academic, vocational or leisure topics, } \\
\text { marking clearly the relationships between ideas. }\end{array}$ \\
\hline $\begin{array}{l}\text { Vantage } \\
\text { Indepen }\end{array}$ & $\begin{array}{l}\text { Can interact with a degree of fluency and spontaneity that } \\
\text { makes regular interaction with native speakers quite possible } \\
\text { without imposing strain on either party. }\end{array}$ \\
\hline $\begin{array}{l}\text { Threshold Plus } \\
\text { [Independent User] }\end{array}$ & $\begin{array}{l}\text { Can communicate with some confidence on familiar routine } \\
\text { and non-routine matters related to his/her interests and } \\
\text { professional field. }\end{array}$ \\
\hline ent User] & $\begin{array}{l}\text { le range of simple language to deal with most } \\
\text { o arise whilst traveling. }\end{array}$ \\
\hline $\begin{array}{l}\text { Waystage Plus [Basic } \\
\text { User] }\end{array}$ & $\begin{array}{l}\text { Can interact with reasonable ease in structured situations and } \\
\text { short conversations, provided the other person helps if } \\
\text { necessary. }\end{array}$ \\
\hline $\begin{array}{l}\text { Waystage } \\
\text { User] }\end{array}$ & $\begin{array}{l}\text { Can communicate in simple and routine tasks requiring a } \\
\text { simple and direct exchange of information on familiar matters } \\
\text { to do with work and free time. }\end{array}$ \\
\hline $\begin{array}{l}\text { Breakthrough [Basic } \\
\text { User] }\end{array}$ & $\begin{array}{l}\text { Can interact in a simple way but communication is totally } \\
\text { dependent on repetition at a slower rate of speech, rephrasing } \\
\text { and repair. }\end{array}$ \\
\hline Tourist & $\begin{array}{l}\text { Can ask and tell the date and time of day, follow short, simple } \\
\text { directions and make simple purchases where pointing or other } \\
\text { gesture can support the verbal reference. }\end{array}$ \\
\hline$S$ & ne basic greetings; can say thank you, sorry. \\
\hline
\end{tabular}

Secondly, no other proficiency scales have gone through more detailed validation than North's (2000) scale. From the beginning of scale construction, North conducted qualitative and quantative validation studies that have shown many positive results. He used theories of communicative competence and language use in defining and classifying scale categories and ordered revised descriptors according to their perceived difficulty by teachers using the multi-faceted Rasch measurement model (Linacre, 2003). North's scale was later tested and supported across languages (e.g., English, German, French; North, 2000, 2002a). Furthermore, since North (2000) was 
used as the basis of the Common Reference Levels in the Common European Framework (CEF scales; Council of Europe, 2001), the following validity evidence of the CEF scales can be interpreted as North's (2000) scale: the positive evidence from studies that used self-assessments ${ }^{2}$ (Jones, 2002; North, 2002b) as well as expert judgments (Kaftandjieva \& Takala, 2002) and from studies across several languages (e.g., English, French, Italian in North, 2002b; Finnish in Kaftandjieva \& Takala, 2002).

Thirdly, North's (2000) scale has more levels at the lower end of the scale (i.e., Smattering, ${ }^{3}$ Tourist, Breakthrough, Waystage levels; see Table 1) and covers a wider range of proficiency levels for novice learners than other scales including the CEF scales. This characteristic offers the great advantage of allowing assessment of attainment levels of Japanese JHS students whose speaking ability is likely to be very low. In addition, North's (2000) scale contains various graded levels covering language ability from beginners to very proficient. Therefore, it can be utilized not only for examining attainment levels but also for setting goals of various stages of English language learning, such as junior and senior high school graduates, university students, adults in general, or English teachers, as suggested by Niisato (2003).

Despite these three strong reasons to adopt North (2000), some may claim that the scale may not be appropriate to the Japanese context because it was basically developed with European contexts in mind. However, the author thinks that it is possible to use the scale, with modifications if necessary, for three reasons: its context-free nature, similarity of Japanese and European educational background, and empirical evidence. First, North's scale and the CEF scales are intended to be "context-free in order to accommodate generalizable results from different specific contexts" (Council of Europe, 2001, p. 21). The CEF scales have been linked to various tests outside Europe, including TOEFL (Test of English as a Foreign Language), TSE (Test of Spoken English), TWE (Test of Written English), TOEIC (Test of English for International Communication) (Educational Testing Service, 2005), and STEP BULATS (Business Language Testing Service; Society for Testing English Proficiency Inc., 2004). Thus, it is reasonable to expect the scale to fit the Japanese context. Second, Nekoda and Nekoda (2002) argue that there are similarities in the educational background of Europe and Japan (i.e., use of communicative approach, recent emphasis on accountability, the need to exchange information among practitioners) and they advocate the use of the CEF scales in Japan. Third, two studies (In'nami, 2004; Nekoda, Nekoda, \& Miura, in press) have used the CEF scales and have shown positive results concerning the applicability of the scales to Japanese learners. In'nami (2004) conducted a listening test based on the CEF scales for 361 Japanese learners of English (mainly university students). In his results, there were neither misfitting items nor misfitting persons (i.e., all items and test takers followed the response patterns expected from Rasch analysis), and the order of item difficulty 
was overall the same as predicted from the CEF scales. Nekoda et al. (in press) asked Japanese learners to rate their proficiency ${ }^{1}$ using the CEF scales and analyzed the similarity of expected patterns from these scales and actual patterns using item response theory. The results were that most participants and items behaved in a similar way to the predicted patterns, indicating the usefulness of the CEF scales in Japanese contexts. In sum, this theoretical and empirical support leads to the argument that North's scale, as well as the CEF scales, functions well in Japan. By way of caution, however, this paper also poses a research question (Research Question 1) as to this issue of suitability, and examines it empirically.

While North's (2000) scale includes every proficiency level from beginners to very advanced, as in Table 1, it is unrealistic to expect Japanese JHS students to reach the high levels. The plausible maximum level was considered Waystage Plus because the Course of Study stipulated that 262.5 to 350 hours (105 to 140 classes of 50-minute instructions per year, which are conducted for three years) should be allocated for English lessons in JHSs (Ministry of Education, Science \& Culture, 1989). Van Ek and Trim (1991) state that a Waystage level can be reached after studying 270 to 290 hours, including instruction and self-study time, while a Threshold level takes 645 to 690 hours (Clark, n.d.). Waystage Plus is "a weaker realization of Threshold content, or strong Waystage performance" (North, p. 275), which makes it reasonable to set Waystage Plus as the maximum possible level when only instruction time is considered in the Japanese context.

To date, a speaking test has not been developed that can differentiate speaking ability below the Waystage level and that is based on the CEF or North's scales. The present study thus included the development of a speaking test for Japanese JHS students that can assess ability from Smattering to Waystage Plus levels before examining attainment levels of JHS students (Research Question 2).

\section{Purpose and Research Questions}

The purpose of the study is to examine (a) the degree of applicability of North's (2000) scale to the Japanese context and (b) attainment levels of Japanese junior high school (JHS) students. Accordingly, the following two questions are addressed.

1. To what extent does North's scale suit Japanese JHS students?

2. What levels on North's proficiency scale (an Japanese JHS students reach during three years of English-language study at JHSs?

The distinguishing characteristics of the current study can be summarized as follows. First, the degree of suitability of North's (2000) scale is investigated with Japanese JHS students with a particular focus on speaking ability using a speaking test, whereas In'nami (2004) targeted mostly Japanese university students and listening ability as measured by a listening test, and Nekoda et al. (in press) asked Japanese vocational college, university, graduate school students to self-assess their own overall 
ability. Second, for the first time, attainment levels of JHS students are explored with North's scale as a basis. Third, a speaking test that can assess ability from Smattering to Waystage Plus levels of North's scale is developed and the validity of the test is examined.

\section{Method}

\subsection{Participants}

A total of 171 students aged 14 to 16 years old participated in the current study. All had studied English for about two to three years in Japanese junior high schools (JHSs) $(M=28.97$ [months], $S D=4.45)$. They included 148 third-year students at two public JHSs (JHS-A \& JHS-B) and 23 first-year senior high school (SHS) students at a public (prefectural) SHS $(n=5)$ and at a SHS affiliated with a national university $(n=$ 18). All the students in the third year of the two JHSs participated, whereas all 23 SHS students agreed to take a test at their teachers' request. All the public SHS students were enrolled in the English course and graduated from public JHSs. Approximately $60 \%$ of all students at a national SHS and in an English course at public SHS normally go to university directly after graduation. First-year SHS students were included in this study in order to determine the possible attainment levels of JHS students upon graduation from the school. Their speaking ability was viewed as similar to JHS students' since they had just graduated from JHSs.

\subsection{Test Instrument}

The speaking test was designed to measure the speaking component of school-based proficiency of Japanese JHS students. School-based proficiency is defined as "ability used in comprehending and producing a language obtained through formal instruction and textbooks," adapted from Shohamy (1992). In the current research, "speaking ability" equals school-based speaking proficiency, and in order to assess such proficiency, functions, vocabulary, and grammar were selected based on learned materials specified by the Course of Study (Ministry of Education, Science \& Culture, 1989, 1999). Table 2 shows the correspondence between each task, expected response, descriptor(s) in North and the Course of Study in the speaking test used in this study. North's descriptors and contexts or functions in the Course of Study were matched in order to assess shared aspects of proficiency and achievement.

As seen in Table 3, the speaking test is composed of five tasks that elicit both dialogue (Task 2 with five items and Task 3 with three items, both tasks being scripted role plays) and monologue (Task 1, self-introduction; Task 4, describing ones' favorites; Task 5, explaining differences between two pictures; see Koizumi, 2003 for details). In order to focus on assessing speaking ability, Japanese meanings of an interviewer's questions were presented to a student when he or she seemed to have difficulty in understanding the prompts. Planning time (of one minute) was given only 
in Task 4 in order to reflect North's (2000) descriptors (see Council of Europe, 2001 for details). After a pilot study and the subsequent modification, content relevance was checked by two graduate students majoring in language testing in order to determine whether the tasks paralleled North's (2000) level descriptors and to guarantee the content aspect of validity.

Table 2. Summary of the Speaking Test Tasks

\begin{tabular}{|c|c|c|}
\hline $\begin{array}{l}\text { Task: } \\
\text { Expected Response }\end{array}$ & $\begin{array}{l}\text { North's Proficiency Descriptors } \\
\text { [North's Levels] }\end{array}$ & $\begin{array}{l}\text { Course } \\
\text { Study }\end{array}$ \\
\hline $\begin{array}{l}\text { T1: My name is Kayoko } \\
\text { Oka. I like volleyball. I } \\
\text { have played it for two } \\
\text { years. I like listening to } \\
\text { music. ... }\end{array}$ & $\begin{array}{l}\text { Can describe their family, living conditions, } \\
\text { educational background, present or most } \\
\text { recent job. OR Can produce brief everyday } \\
\text { expressions in order to satisfy simple needs of } \\
\text { a concrete type personal details. [Waystage] }\end{array}$ & $\begin{array}{l}\text { Self- } \\
\text { introduction }\end{array}$ \\
\hline $\begin{array}{l}\text { T2A: I want to go to } \\
\text { Maruya to buy a book. }\end{array}$ & $\begin{array}{l}\text { Can discuss what to do, where to go. } \\
\text { [Waystage] }\end{array}$ & $\begin{array}{l}\text { To explain, } \\
\text { To describe }\end{array}$ \\
\hline $\begin{array}{l}\text { T2B: Good-bye. / } \\
\text { T2C: Hello. }\end{array}$ & Can use some basic greetings. & Greetings \\
\hline T2D: What time is it? & Can ask time of day. & To question \\
\hline T2E: I'm sorry. & Can say sorry. & To apologize \\
\hline
\end{tabular}

T3A: Do you like this Can ask simple questions on very familiar To question school? topics. OR Can ask questions about personal details. [Breakthrough]

T3B: Where do you live Can ask questions about personal details, such To question now? as where they live. [Breakthrough] T3C: Where did you Can ask questions. [Waystage] To question live before?

T4: I like Ayumi Can describe people in simple terms. because she is cute. [Waystage] To describe

T5: The ball was under Describe something in a simple list of points. To explain, the table, but ... [Waystage Plus] To describe Note. $\mathrm{T}=$ Task. Tasks 1 and $3 \mathrm{~A}$ had two descriptors each because their expressions were very similar and because they were at the same level.

Analytic rating scales used in the current study had four categories: Task fulfillment, Vocabulary volume, Fluency, and Accuracy. All of these shared both proficiency (Bachman \& Palmer, 1996; North, 2000) and achievement (Ministry of Education, Science \& Culture, 1999; Wada, 2000) aspects. There were four levels for each category ( 0 to 3; see Appendix). Task fulfillment was designed for Tasks 2 and 3, which elicited short utterances, while the latter three were for Tasks 1, 4, and 5 for extended speech. Each rating category (e.g., Task fulfillment, Fluency) is referred to as a test item hereafter. 
Table 3. Examples of the Speaking Test Tasks (All written in Japanese)

Task 1 Please introduce yourself for 90 seconds. Please talk about many things. When you have finished reading, please raise your head (i.e., no planning time, the same as in Tasks 3 and 5).

Topic Examples: name, grade, school, favorites, family, and friends

Task 2 You are talking with your friend. Express what you're talking about as shown in the picture (see Koizumi, 2003a, for a picture).

Elicited sentences: I want to go to Maruya to buy a book./Good bye./Hello./ What time is it now?/I am sorry.

Task 3 You are a reporter for your school newspaper. You are going to interview a boy who transferred from another school last week, and then write a report. Look at your notes and ask him questions about himself. The teacher in front of you will play the role of the new student.

Notes: Things to ask the boy (1)Do you like this school?

(2) Where do you live now? (3)Where did you live before?

Task 4 Tell me about your favorite singer, TV programs, or animal for 90 seconds. You have one minute to prepare. Example: reasons, how popular they are

Task 5 Your brother is mischievous. While you were at school, he scattered your things about your room. When you scolded him about it, he said, "nothing has changed at all." Tell him how the room has changed by comparing how it was before with how it is now. You have 90 seconds to speak. (see Koizumi, 2003, for pictures)

\subsection{Procedures}

The speaking test was conducted in July 2002, on a face-to-face, one-on-one basis with an interviewer and a student sitting in a room alone for approximately 15 minutes. Eleven non-native English speakers with appropriate speaking ability for administering the test were trained as interviewers. All students were informed that that they would speak English in the test, but they were not informed about the test contents. Although Tasks 1, 4, and 5 required the students to speak for 90 seconds, interviewers moved to the next task when there was a silence of at least. 15 seconds, in order to avoid pressuring the students. During the speaking test, all the utterances were tape-recorded and later transcribed.

Ratings where subjective judgments could be involved (e.g., Task fulfillment, in contrast to the count of uttered words) were done all by the author and half by half by two graduate students (non-native speakers of English), who attended the rater training session.

\subsection{Analyses}

The two research questions were answered using FACETS for Windows 3.45.2 (Linacre, 2003), which implements the multi-faceted Rasch measurement model and produces item difficulty estimates, person ability estimates, and fit indices. Rasch analysis has three main advantages over classical test analysis (Henning, 1987). First, item difficulty can be estimated independently of the sample size and the ability of the 
sample group. Second, person ability can be estimated independently of the number of items used and the difficulty of the items. Third, the reliability and standard error can be obtained for each item and test taker.

An alpha level of .05 was used for all statistical tests.

Research Question 1 is answered in two ways: first, by checking the ratio of misfitting items and misfitting students, and second, by comparing the order of item difficulty with the one predicted by North's (2000) scale. In relation to the first method, misfitting items and persons reveal that their scoring patterns are different from common response patterns (McNamara, 1996). If the percentage of misfitting items/persons is small, the obtained data is consistent with the Rasch model, which can be considered to reflect North's scale dimension. A similarity between the predicted and actual order of item difficulty suggests suitability to the Japanese contexts. Research Question 2 is solved by relating speaking tasks to North's scale descriptors and by setting up cut-off levels, using the level-specified tasks.

The validity of the speaking test, or, strictly speaking, the validity of inferences and uses of the speaking test developed in this study, is also examined because of its importance in test development and use (e.g., Bachman, 1990). Although validity has been considered a unitary concept, it is useful to deconstruct unified validity into six aspects to conduct validation studies (Messick, 1996), three of which are explored in the current study. First, the content aspect is examined by experts by checking "the hypothesized match between test items or tasks and the construct that the test is intended to measure" (Chapelle, 1999, p. 260), which was investigated in the section of Test Instrument (see section 4.2). Second, the structural aspect is examined by investigating "the extent to which observed dimensionality of response data is consistent with the hypothesized dimensionality of a construct" (Chapelle, p. 261). This analysis is a part of Research Question 1. Third, the generalizability aspect is observed by testing the hypotheses "based on a theory of the construct which includes how it should behave differently across groups of test-takers, time, instruction, or test task characteristics" (Chapelle, p. 262). This study focuses on a difference in performance across groups.

\subsection{Main Results}

\section{Results}

The data of 17 items (i.e., eight items in Task fulfillment for Tasks 2 and 3, and nine items in Vocabulary volume, Fluency, and Accuracy for Tasks 1, 4, and 5), 171 examinees, and three raters were used for computing item difficulty, students' ability, and rater severity. The Rasch measurement model assumes unidimensionality, which means that a test assesses one type of ability or content. If the assumption of unidimensionality is met, the test provides validity evidence of the structural aspect of test scores. There are two methods to check for unidimensionality: (a) use factor 
analysis before using FACETS, and (b) calculate fit statistics (McNamara, 1996). This study used the latter to verify unidimensionality.

After the initial calibration, fit statistics were examined in order to answer Research Question 1. Items and examinees were considered acceptable when infit mean square statistics (IMSSs) were within the mean plus or minus two standard deviations (i.e., $M \pm 2 S D$ when $n=30$ or more; McNamara, 1996). The values over the higher end (i.e., more than $M+2 S D$ ) suggest misfitting items or students. In the present study, all item IMSSs were within this range $(1.1 \pm 2 * 0.4=0.3-1.9$; see Table 4). All examinee IMSSs were within this range $(1.0 \pm 2 * 0.5=0.0-2.0)$ except seven misfitting students (4\%). The percentage exceeded $2 \%$ of the acceptable criteria of having misfitting students (McNamara, 1996). Since this may indicate problematic aspects of North's (2000) scale, misfitting students' performance are explored in section 5.2. Since most fit statistics of items and persons were acceptable, the unidimensionality was considered to be satisfied to a large extent, which suggests validity evidence of the structural aspect. All reliabilities were high (item reliability $=.99$; person reliability $=.92$; rater reliability $=.00$ [which means the reliability of 1.00 ; Linacre, 1991, p. 86]; exact agreements of raters $94 \%$ ), which also serves as validity evidence of the structural aspects.

Table 4. Task Results of Item Difficulty, Fit Indices, and Predicted Levels

\begin{tabular}{lcccc}
\hline Item & Measure & SE & IMSS & Predicted level \\
\hline T5 (Comparison) Accuracy & $\mathbf{1 . 7 1}$ & 0.13 & 0.92 & Waystage Plus \\
T3C (Where did you live before?) TF & 1.53 & 0.07 & 0.86 & Waystage \\
T2A (I want to go to Maruya ...) TF & 1.03 & 0.06 & 0.54 & Waystage \\
T4 (Favorites) Vocabulary & $\mathbf{0 . 8 9}$ & 0.11 & 0.44 & Waystage \\
T5 (Comparison) Fluency & 0.88 & 0.11 & 1.37 & \\
T5 (Comparison) Vocabulary & 0.73 & 0.11 & 0.52 & \\
T3B (Where do you live now?) TF & 0.73 & 0.06 & 0.83 & Breakthrough \\
T1 (Self-Introduction) Vocabulary & 0.37 & 0.10 & 0.39 & Waystage \\
T3A (Do you like this school?) TF & $\mathbf{0 . 3 6}$ & 0.06 & 0.74 & Breakthrough \\
T2D (What time is it now?) TF & $\mathbf{- 0 . 2 2}$ & 0.07 & 1.17 & Tourist \\
T4 (Favorites) Accuracy & -0.50 & 0.10 & 1.60 & \\
T4 (Favorites) Fluency & -0.57 & 0.10 & 1.32 & \\
T2C (Hello.) TF & -0.71 & 0.08 & 1.68 & Smattering \\
T2B (Good-bye.) TF & -0.72 & 0.08 & 1.18 & Smattering \\
T1 (Self-Introduction) Fluency & -1.62 & 0.12 & 1.45 & \\
T2E (I'm sorry.) & $\mathbf{- 1 . 6 8}$ & 0.12 & 1.10 & Smattering \\
T1 (Self-Introduction) Accuracy & -2.22 & 0.13 & 1.89 & \\
\hline Note. Measure Item & &
\end{tabular}

Note. Measure = Item difficulty estimate; $S E=$ Standard error; IMSS = Infit mean square statistic; Predicted level = The level in North's (2000) scale (see "Levels" in Table 2). For Tasks 1, 4, and 5, Predicted levels were only written for the rating category with the highest difficulty of the three. ()$=$ Content or expected response. TF $=$ Task fulfillment. Boldfaced $=$ the easiest item at a certain level. Positive values of measures show more difficult items than the average of 0 . Separation $=11.26$. 
Table 5. Results from FACETS

\begin{tabular}{|c|c|c|c|c|}
\hline \multicolumn{3}{|c|}{$\mid$ Meas $\mid+$ Examinee $\mid$-Scale } & $|-J u|$ & \multirow{2}{*}{$\begin{array}{l}\text { Level } \\
\text { Waystage }\end{array}$} \\
\hline 1 & & 1 & 11 & \\
\hline 1 & & | T5_Accuracy [Waystage+, 1.71] & i & \\
\hline 1 & *. & T3(3)_Before [Waystage, 1.53] & 1 & \\
\hline 1 & * & 1 & 11 & \\
\hline 1 & * & I & 11 & \\
\hline i & * & i & 1 & Break- \\
\hline 1 & **. & 1 & 11 & through \\
\hline $1+$ & ** & + T2(1_Maruya [Waystage, 1.03] & & \\
\hline 1 & **. & I T4_Vocabulary [Waystage, 0.89 ] T5_Fluency & 11 & \\
\hline 1 & *. & I T3(2)_Live [Breakthrough, 0.73] T5_Vocabulary & 11 & \\
\hline 1 & * & 1 & 11 & \\
\hline i & $* * * *$ & i & 11 & \\
\hline 1 & $* * *$ & I & 11 & Tourist \\
\hline 1 & $*$. & | T1_Vocabulary [Waystage, 0.37] & & \\
\hline 1 & * & | T3(1)_School [Breakthrough, $0.3(i]$ & i i & \\
\hline 1 & **. & -5 & $1 i$ & \\
\hline $1 \quad 1$ & $* * * *$ & 1 & 1 & \\
\hline * $0 *$ & $* * * *$ & * & * * & \\
\hline I & ******. & I & 11 & Smatter- \\
\hline 1 & $* * * * * * *$ & | T2(4)_Time [Tourist, -0.22] & i i & \\
\hline 1 & ***. & I & 11 & \\
\hline 1 & $* * *$ & I & 11 & \\
\hline 1 & $* * * * * * *$ & I T4_Accuracy T4_Fluency & 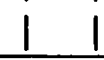 & \\
\hline I & *. & | T2(3)_Hel lo [Smattering, -0.71$]$ & 11 & \\
\hline I & & | T2(2)_Bye [Smattering, -0.72] & 11 & \\
\hline 1 & *** & 1 & 11 & \\
\hline 1 & * & 1 & $\left|\begin{array}{ll}1 & 2\end{array}\right|$ & \\
\hline$+-1+$ & ** & + & $+3+$ & \\
\hline 1 & **. & I & 11 & \\
\hline I & . & I & 11 & (No \\
\hline I & *. & I & 11 & Level) \\
\hline 1 & * & 1 & 11 & \\
\hline i & & 1 & 11 & \\
\hline 1 & *. & I T1_Fluency T25)_Sorry [Smar:tering, -1.68] & 11 & \\
\hline 1 & $* *$ & 1 & 11 & \\
\hline 11 & *. & I & & \\
\hline$+-2+$ & & + & & \\
\hline $1 \quad 1$ & & 1 & 11 & \\
\hline 1 & & | T1_Accuracy & 11 & \\
\hline
\end{tabular}

Note . Meas $=$ Measure; $\mathrm{Ju}=$ Judges; ${ }^{*}=2$ examinees; . $=1$ examinee; $\mathrm{T}=$ Task; $[\mathrm{]}=$ Predicted level and its difficulty estimate by North (2000). This sign was put only at the rating category with the highest difficulty of the three. For a lack of space, 10 high and 3 low examinees were omitted in this table. 
Table 5 shows students' ability ("Examinee" column), item difficulty ("Scale" column), and rater severity ("Ju[dges]" column) on the same scale ("Meas[ure]" column) with zero specified as the average. In the second column, students with higher speaking ability are located above zero, whereas students with lower speaking ability can be seen below zero. The test takers reflected a diverse range of speaking ability ( $M$ $=0.00, S D=1.10$ ). The third column contains the most difficult item at the top (Task 5 Accuracy) and the easiest item at the bottom (Task 1 Accuracy) ${ }^{4}$. There were a variety of items with a wide range of difficulty $(M=0.00, S D=1.12)$. In the fourth column, the three raters' severity was similar at around minus one on the scale, which indicates that they were similarly lenient in rating $(M=-0.95, S D=0.03)$.

In order to investigate the attainment levels of speaking ability of Japanese JHS students, two steps were taken. First, the most difficult rating category (e.g., Task 4 Vocabulary) of the three (i.e., Vocabulary volume, Fluency, and Accuracy) of Tasks 1 , 4, and 5, was considered to best represent North's (2000) descriptor because students could be regarded as having achieved a certain task when their ratings were satisfactory in all of the three rating categories. The results show that the overall trend of level ordering was similar to the levels predicted by North, as seen in Table 4 . One obvious difference between actual item difficulty and the predicted level was seen in Task 1 (Self-introduction), which was located in the Breakthrough level range, not in the Waystage level range. This may be because the test takers may have memorized fixed phrases that can be used for self-introduction, and achieved the task easily since this task may be repeated many times in class. The agreement ratio between the current study results and the predicted levels was $91 \%$ (i.e., 10/11*100), which indicates overall applicability of North's scale to Japanese JHS students. Since Task 1 Vocabulary volume behaved differently from the prediction, its result was excluded from the following interpretation.

Second, cut-off points at each level corresponding to North's scale were determined based on the item difficulty. The present study set the cut-off points where $70 \%$ (University of Cambridge ESOL, 2003) of a level was achieved, specifically $70 \%$ of the interval ${ }^{5}$ from the easiest item at that level to the easiest item at the next level. Thus, the cut-off points can be seen in Table 6 .

Table 6 shows the proportion of students who reached each speaking level. For instance, a student with a speaking ability estimate of 1.47 has school-based speaking proficiency at the Waystage level. It was found that the group of senior high school (SHS) students at both public and national schools $(M=1.75, S D=0.89)$ had significantly higher speaking ability estimates than the group of JHS students at the other two schools (JHSs-A and B, $M=-0.27, S D=0.87$ ), $t(169)=-10.38, p<.05$, which shows the validity evidence of the generalizability aspect.

The results are that the patterns of the public JHS students were very similar. Average third-year public JHS students reached the Smattering level at both schools, 
and about $10 \%$ of them reached the Breakthrough level, while the maximum level was Waystage level. In the Common European Framework scales, learners at the Breakthrough, Waystage, and Waystage Plus levels are considered "Basic users," but most JHS students did not reach these levels. The results of all five students at a public SHS reached the Breakthrough level or more, with the highest attainment level being the Waystage level. In contrast, all students at a national SHS reached at least the Tourist level, with the maximum level of Waystage Plus or above. Since all the students at SHS-P graduated from public JHS, thi: results derived from JHS-A, JHS-B, and SHS-P can be interpreted as public JHS students' speaking attainment levels. Since the results of this study were not derived from a random sampling procedure, the generalization may be limited, but the fact that the patterns of the two public schools were similar supports the view that this result is generalizable to some extent.

Table 6. Number and Percentage (\%) of Participants at Each Speaking Level

\begin{tabular}{llcccc}
\hline Ability & North's Level & JHS-A & JHS-B & SHS-P & SHS-N \\
\hline $\mathbf{2 . 1 8}$ or above & Waystage Plus or above & $0(0)$ & $0(0)$ & $0(0)$ & $7(39)$ \\
$\mathbf{1 . 4 6}$ to 2.17 & Waystage & $1(1)$ & $1(1)$ & $1(20)$ & $\underline{5(28)}$ \\
$\mathbf{0 . 7 3}$ to 1.45 & Breakthrough & $7(10)$ & $7(9)$ & $\underline{4(80)}$ & $4(22)$ \\
$\mathbf{0 . 1 9}$ to 0.72 & Tourist & $18(25)$ & $8(11)$ & $0(0)$ & $2(11)$ \\
$\mathbf{- 0 . 6 6}$ to 0.18 & Smattering & $\underline{33(46)}$ & $\underline{34(45)}$ & $0(0)$ & $0(0)$ \\
up to -0.65 & Below Smattering & $13(18)$ & $26(34)$ & $0(0)$ & $0(0)$ \\
\hline & Total & $72(100)$ & $\mathbf{7 6 ( 1 0 0 )}$ & $5(100)$ & $18(100)$ \\
\hline
\end{tabular}

Note. JHS-A = Public junior high school A; JHS-B = Public junior high school B; SHS-P = Public senior high school; SHS-N = National senior high school; Underlined $=$ Average level of the group. Boldfaced $=$ Cut-off point at each level.$^{6}$

\subsection{Results of Misfitting Students}

Among the seven misfitting students found in Main Results, most $(n=5,71 \%)$ had very low speaking ability and belonged to the Below Smattering level, whereas the other two were at either the Tourist $(n=1)$ or Breakthrough $(n=1)$ levels. When their unexpected responses reported by FACETS were examined, some reasons for misfitting were revealed (see Table 7), such as misunderstandings of prompts (Student $\mathrm{A}$ b), and $\mathrm{c}$ )), which may suggest the need for further revision of items. Even when reasons for misfitting were not obvious at first sight, further analysis showed that there were consistent patterns in the following tasks: Task 1 and Task 2B, 2C, 2E. First, Task 1 was problematic for four examinees (Students B a), D a), E a), and G). Two students at the Below Smattering level (Students E a), and G) only said their names and finished the utterances, which were produced fluently, so they obtained higher fluency ratings than expected. However, the examinee at the Tourist level (Student B) made some noticeable mistakes, probably because he tried to speak as long as he could, while not depending on memorized phrases, and he thus obtained a lower accuracy rating than expected. Task 1 was detected as problematic in the previous section in terms of the 
Table 7. Unexpected Responses Derived from Misfitting Students

\begin{tabular}{|c|c|c|}
\hline Ability & Utterance & Possible reason \\
\hline $\begin{array}{l}\text { Student } \\
\text { A: } 0.80 \\
\text { [Break- } \\
\text { through } \\
\text { level] }\end{array}$ & $\begin{array}{l}\text { a] T5 (Pictures) Accuracy: A ball was ... [silence] } \\
\text { under the table. But now the ball ... is on the } \\
\text { desk. ... The guitar is was the guitar was ... in ... } \\
\text { the box. But now the guitar ... is on the bed. } \\
\text { [Better] } \\
\text { b] T2B (Good-bye.): O.K. [Worse] } \\
\text { c] T2C (Hello.): I'm sorry. I'm late. [Worse] }\end{array}$ & $\begin{array}{l}\text { b], c] } \\
\text { Misunderstanding of } \\
\text { the prompt }\end{array}$ \\
\hline $\begin{array}{l}\text { B: } 0.56 \\
\text { [Tourist] }\end{array}$ & $\begin{array}{l}\text { a] T1 (Self-introduction) Accuracy: Let my my let } \\
\text { me introduce myself. My name is ** [name]. eh I } \\
\text { I am eeto one one grade eh high school high } \\
\text { school mate. eh ah I go to eh my ... I go I go to } \\
\text { school I go to school of ** daifuzoliu [i.e., } \\
\text { university-afjiliated]. ... I I like to I like to eh read } \\
\ldots \text { the book ah and listen to music. ... O.K. eh I } \\
\text { My family member ... name is a father and a } \\
\text { mother and me and little sister. [To be continued] } \\
\text { [Worse] } \\
\text { b] T2C (Hello.): ... [Worse] }\end{array}$ & $\begin{array}{l}\text { b] Some words were } \\
\text { uttered but it was } \\
\text { difficult to } \\
\text { understand them. } \\
\text { Maybe due to a } \\
\text { mechanical problem } \\
\text { of a recorder }\end{array}$ \\
\hline $\begin{array}{l}\text { C: }-1.61 \\
\text { [Below] }\end{array}$ & $\begin{array}{l}\text { a] T4 (Favorites) Accuracy: Yes. [Better] } \\
\text { b] T2E (I'm sorry.): ... [Worse] }\end{array}$ & $\begin{array}{l}\text { Rating scale problem } \\
\text { Unknown }\end{array}$ \\
\hline $\begin{array}{l}\text { D: }-1.77 \\
{[\text { Below] }}\end{array}$ & $\begin{array}{l}\text { a] T1 (Self-introduction) Accuracy: Wakarimasen } \\
\text { [i.e., I don't know]. [Worse] } \\
\text { b] T2E (I'm sorry.): I'm sorry. [Worse] }\end{array}$ & $\begin{array}{l}\text { Unknown } \\
\text { Rater's mistake } \\
\end{array}$ \\
\hline $\begin{array}{l}\text { E: }-1.77 \\
{[\text { Below] }}\end{array}$ & $\begin{array}{l}\text { a] T1 (Self-introduction) Fluency: My name is **. } \\
\text { [Better] } \\
\text { b] T2E (I'm sorry.): ... [Worse] }\end{array}$ & $\begin{array}{l}\text { Unknown } \\
\text { Unknown }\end{array}$ \\
\hline $\begin{array}{l}\text { F: }-1.93 \\
{[\text { Below] }}\end{array}$ & $\begin{array}{l}\text { a] T2B (Good-bye.): See you. [Better] } \\
\text { b] T2C (Hello.): Hello. [Better] } \\
\text { c] T2E (I'm sorry.): ... [Worse] }\end{array}$ & $\begin{array}{l}\text { Unknown } \\
\text { Unknown } \\
\text { Unknown }\end{array}$ \\
\hline $\begin{array}{l}\text { G: }-2.98 \\
\text { [Below] }\end{array}$ & $\begin{array}{l}\text { T1 (Self-introduction) Vocabulary, T1 Accuracy, } \\
\text { T1 Fluency: My name is }{ }^{* *} \text {. [Better] }\end{array}$ & Unknown \\
\hline
\end{tabular}

Note. Below = Below Smattering; ( $)=$ Content or expected response; Better $=$ Better performance than expected; Worse $=$ Worse performance than expected.

level ordering and may need cautious interpretation, although Task 1 Vocabulary volume, Fluency, and Accuracy did not misfit overall (see Table 4). However, these are problems of Task 1, not a problem of North's (2000) scale.

Second, the expected responses of problematic items (i.e., Task 2B, 2C, and 2E) 
are all fixed phrases. Student $\mathrm{F}$ did not produce the easiest item (Task $2 \mathrm{E}$ I'm sorry.) but accomplished more difficult items (Tasks 2B Good-bye. and 2C Hello.), whereas Students B, C, and E performed worse than the prediction. This indicates that the difficulty order of these three formulaic expressions may be unstable, especially for students at the Below Smattering level. However, the three items all reflected the Smattering level descriptors, and no orders exist between these descriptors in North's (2000) scale. This indicates that problems of Tasks $2 \mathrm{~B}, 2 \mathrm{C}$, and $2 \mathrm{E}$ did not come from the non-suitability of North's scale. To sum up, since most unexpected responses were explained by reasons not relevant to North's problems, the scale seems to suit Japanese JHS students overall as it is.

\section{Discussion}

This study examined two research questions: (a) to what extent North's (2000) scale suits junior high school (JHS) students in Japan, and (b) what speaking level on North's scale Japanese JHS students can reach during three years of English-language study at JHSs. The results for (a) show that there were no misfitting items, and the level order of the items in comparison with the level order predicted by North was consistent overall except for one item. Although there was a rather large percentage of misfitting test takers $(4 \%)$, the reasons of misfitting usually did not result from problems of North's scale. Therefore, it can be concluded that North's (2000) scale suits Japanese JHS students overall without any modification, as suggested by In'nami (2004) and Nekoda et al. (in press).

The findings of Research Question 2 were as follows: Public third-year JHS students on average have school-based speaking proficiency at the Smattering level, and students with high proficiency at public JHSs reach the Breakthrough or Waystage levels of North's language proficiency scale. In addition, when all students at a national JHS are taken into consideration, the maximum level is expanded to include the Waystage Plus or above level. This result is consistent with the expectation that the Waystage Plus level is the highest level of speaking ability attainable for JHS students upon graduation based on the instruction time stipulated by the Ministry of Education, Science and Culture (1989). One thing to be noticed is that these attainment levels are set on the understanding that the test content is limited to areas that students have already studied at school. Thus, when the content is not restricted, the result of attainment levels may be similar or lower.

Based on the current attainment levels, realistic goals of English language teaching should be determined. Although it is difficult to define the term "realistic," the author thinks that realistic goals should be set at levels that are a little high but still attainable when teachers and students make an effort. Thus, the goals at the JHS graduation should be set at the Tourist or Breakthrough levels for average public JHS students, and the Waystage, Waystage Plus, or Threshold levels for those with high 
proficiency.

The information on the achievement level of Japanese JHS students can be useful not only for serving as the basis for realistic final goal settings but also for deciding on term- or year-long teaching objectives by selecting descriptors from each level. For example, in "Transactional information exchange," people at each level can successfully complete the following behaviors, the descriptors of which teachers can use in setting a teaching goal and evaluation categories and criteria (North, 2000):

Waystage Plus level: "Can give simple directions and instructions (e.g., explain how to get somewhere, how to play a game)"

Waystage level: "Can ask and answer questions about what they do in free time"

Breakthrough level: "Can ask and answer questions about personal details, such as where they live, people they know, and things they have"

Tourist level: "Can ask and tell day, time of day and date" (pp. 394-395)

As for the validity evidence of the speaking test developed in this study, three aspects of positive validity evidence were presented: content, structural, and generalizability aspects. The results suggest that there is an acceptable level of validity. Therefore, the tasks in the speaking test developed in this study can be used for estimating students' speaking ability levels up to Waystage Plus levels. In order to learn what speaking level students have reached, conducting and evaluating a few of the developed tasks can be sufficient to obtain approximate estimates although more tasks may clearly need to be administered in order to obtain more precise results.

Future research should examine senior high school and college students' attainment levels by increasing the target levels and the number of tasks in the speaking test. Moreover, not only school-based proficiency but also a whole range of proficiency needs to be assessed. Additionally, more aspects of validity should be examined in terms of the speaking test developed in this study. Lastly, more precise methods need to be used for linking tests to North's scale and the CEF scales, based on Council of Europe (2003).

\section{Acknowledgments}

This paper is based on my master's thesis submitted to the University of Tsukuba. An earlier version of this paper was presented at the 29th annual meeting of the Japan Society of English Education in the South Tohoku Region, Miyagi, August 9, 2003. I am thankful to Professor Akihiko Mochizuki, Mr. Yo In'nami, and Ms. Maki Shimizu, University of Tsukuba and many others for their valuable suggestions.

\section{Notes}

1. See Erikawa (2004) and Nihon Gaikokugo Kyouiku Kaizen Kyougikai (2003, 
2004), for example, for other problems of the Action Plan.

2. The degree of validity of self-assessments is controversial. However, three self-assessment studies (Jones, 2002; Nekoda et al. in press; North, 2002b) related to the $\mathrm{CEF}$ scales were considered to have some validity because, according to Oscarson (1997), self-assessments are more valid when conducted "in relation to concrete descriptions of more narrowly defined linguistic situations" (p. 183), which is true in the case of the papers cited above.

3. Although North (2000) does not consider "Smattering" a level, the present research treated it as one level in order to differentiate subtle changes in speaking proficiency.

4. The reason why Accuracy of Tasks 1 and 4 was the least difficult, whereas that of Task 5 was the most difficult may be that the former two tasks seemed to elicit more formulaic expressions, while Task 5 seemed to encourage students to construct their own utterances.

5. The reason why cut-off points were determined at $70 \%$ of the intervals and not at $70 \%$ of the tasks was that the number of items at each level varied (e.g., one item at the Tourist level and three at the Smattering level) and the $70 \%$ criterion of the tasks could lead to a differential setting of difficulty levels.

6. Cut-off points were calculated as follows:

-0.66 at the Smattering level (i.e., $[-0.22-(-1.68)] * 0.7+[-1.68]=1.02+[-1.68])$;

0.19 at the Tourist level (i.e., $\left.[0.36-(-0.22)]^{*} 0.7+[-0.22]=0.41+[-0.22]\right)$;

0.73 at the Breakthrough level (i.e., $\left.[0.89-(0.36)]^{*} 0.7+[0.36]=0.37+[0.36]\right)$; and

1.46 at the Waystage level (i.e., $[1.71-(0.89)] * 0.7+[0.89]=0.57+[0.89])$. The cut-off point at the Waystage Plus or above level was determined as 2.18 (i.e., $[0.37+0.57] / 2+1.71=0.47+1.71)$ using the average of the intervals of the Breakthrough (0.37) and Waystage (0.57) as the interval of the Waystage Plus or above level. The Smattering and Tourist level intervals were not used because there was only one task at the Tourist level s. the cut-off points of the Smattering and Tourist levels may be unstable. This procedure is based on North (2000), in which all the levels had almost equal intervals. It should be noted that the cut-off point of the Waystage Plus or above level is an estimate, so the interpretation should be make cautiously.

\section{References}

Bachman, L. F. (1990). Fundamental considerations in language testing. Oxford University Press.

Bachman, L. F., \& Palmer, A. S. (1996). Language testing in practice. Oxford University Press.

Chapelle, C. A. (1999). Validity in language assessment. Annual Review of Applied Linguistics, 19, 254-272.

Clark, C. (n.d.). The Common European Framework of reference. Retrieved October 
29, 2003, from http://www.unipd.it/cla/CoE/coe_index.htm

Council of Europe. (2001). Common European Framework of reference for languages.

Cambridge University Press.

Council of Europe. (2003). Manual for relating Language Examinations to CEF.

Retrieved March 29, 2005, from

$\mathrm{http} / / / \mathrm{www} . c o e . i n t / \mathrm{T} / \mathrm{E} / \mathrm{Cultural}$ _Co-operation/education/Languages/Language Policy/Manual/

Davies, A., Brown, A., Elder, C., Hill, K., Lumley, T., \& McNamara, T. (1999). Dictionary of language testing. Cambridge University Press.

Educational Testing Service (ETS). (2005). Mapping Test Scores onto the Common European Framework (CEF). Retrieved March 29, 2005, from http://www.ets.org/ell/cef.html

Erikawa, H. (2004). Eigo senryaku keikaku no hihanteki kousatsu [A critical examination of "A Strategic Plan to Cultivate "Japanese with English Abilities"']. Bulletin of Chubu English Language Education Society, 34, 321-328.

Foster, P., Tonkyn, A., \& Wigglesworth, G. (2000). Measuring spoken language: A unit for all reasons. Applied Linguistics, 21, 354-375.

Henning, G. (1987). A guide to language testing. Boston, MA: Heinle \& Heinle.

In'nami, Y. (2004). The effects of listening proficiency and task on the listening test performance of Japanese EFL learners. Unyublished master's thesis, University of Tsukuba, Japan.

Jones, N. (2002). Relating the ALTE Framework to the Common European Framework of Reference. In J. C. Alderson (Ed.), Common European Framework of Reference for Languages: Case studies (pp.167-183). Strasbourg Cedex, France: Council of Europe.

Kaftandjieva, F., \& Takala, S. (2002). Council of Europe scales of language proficiency: A validation study. In J. C. Alderson (Ed.), Common European Framework of Reference for Languages: Case studies (pp. 106-129). France: Council of Europe.

Koizumi, R. (2003). Development of a speaking test for Japanese junior high school students. Unpublished master's thesis, University of Tsukuba, Japan.

Linacre, J. M. (1991). A user's guide to FACETS. Chicago: MESA Press.

Linacre, J. M. (2003). Facets: Rasch-measurement computer program (Version 3.45.2) [Computer software]. Chicago: MESA Press.

McNamara, T. (1996). Measuring second language performance. Essex, U.K.: Addison Wesley Longman.

Messick, S. (1996). Validity and washback in language testing. Language Testing, 13, 241-256.

Ministry of Education, Culture, Sports, Science \& Technology (MEXT). (2003). Regarding the establishment of an action plan to cultivate "Japanese with English abilities." Retrieved March 29, 2005, from http://www.mext.go.jp/english/topics/03072801.htm

Ministry of Education, Science \& Culture. (1989). Chugakkou shidousho gaikokugo hen [Instruction guidelines for junior high school]. Tokyo: Kairyudo.

Ministry of Education, Science \& Culture. (1999). Chugakkou gakushuu shidou youryo (heisei 10 nen 12 gatsu) kaisetsu-gaikokugo hen-- [Explanation of the Course of Study for junior high school concerning foreign languages]. Tokyo: Tokyo 
shoseki.

Nekoda, H., \& Nekoda, K. (2002). Significance of Common European Framework of Reference for Languages: For co-operation among ELT practitioners in Japan. Annual Review of English Language Education in Japan, 13, 219-228.

Nekoda, H., Nekoda, K., \& Miura, S. (in press). The Common European reference scales: A study of their applicability to Japanese learners of English. 『教育学研 究ジャーナル』, 1 .

Nihon Gaikokugo Kyouiku Kaizen Kyougikai (The Japan Council for Improvement in Foreign Language Education). (2004). Nihon no gaikokugo kyouiku no kaizen ni kansuru teigen: "Eigo ga tsukaeru nihonjin" no ikusei no tameno koudou keikaku wo tadasu [A proposal for improvement of foreign language education in Japan: Examination of "an Action Plan to Cultivate 'Japanese with English Abilities"']」 . English Teachers' Magazine, 53(5, August), 44-47.

Nihon Gaikokugo Kyouiku Kaizen Kyougikai. (2003). Gaikokugo kyouiku no kaizen ni kansuru teigen: "Eigo ga tsukaeru nihonjin" no ikusei no tameno senryaku kousou -eigo ryoku and kokugo ryoku zoushin plan wo tou [A proposal to improvement of foreign language education: Questioning "an Strategic Plan to Cultivate 'Japanese With English Abilities'"]」 . English Teachers' Magazine, 52(4, July), 44-47.

Niisato, M. (2003). Eigo unyou nouryoku no dankaiteki tassei kijun wo shimesu [Presenting graded achievement criteria for English proficiency]」. ELEC Bulletin, 110, 14-18.

North, B. (2000). The development of a common framework scale of language proficiency. New York: Peter Lang.

North, B. (2002a). Developing descriptor scales of language proficiency for the CEF Common Reference Levels. In J. C. Alderson (Ed.), Common European Framework of Reference for Languages: Case studies (pp. 87-105). France: Council of Europe.

North, B. (2002b). A CEF-based self-assessment tool for university entrance. In J. C. Alderson (Ed.), Common European Framework of Reference for Languages:

Case studies (pp. 146-166). Strasbourg Cedex, France: Council of Europe.

Oscarson, M. (1997). Self-assessment of foreign and second language proficiency. In C. Clapham, \& D. Corson (Eds.), Language testing and assessment (pp. 175-187). Dordrecht, the Netherlands: Kluwer Academic.

Shohamy, E. (1992). Beyond proficiency testing: A diagnostic feedback testing model for assessing foreign language learning. Modern Language Journal, 76, 513-521.

Society for Testing English Proficiency Inc. (2001). The STEP Test evaluation standards. Retrieved March 29, 2005, from $\mathrm{http}: / / w w w . e i k e n . o r . j p / e n g l i s h / e v a l u a t e / i n d e x . h t m l$

Society for Testing English Proficiency Inc. (2004). STEP (The Society for Testing English Proficiency, Inc) BULATS (Business Language Testing Service) kekka tsuuchi [reporting of results]. Retrieved March 29, 2005, from http://www.eiken.or.jp/bulats/kekka.html

University of Cambridge English for Speakers of Others Languages (ESOL). (2003). KET (Key English Test) Handbook 2003. Ritrieved March 29, 2005, from http://www.cambridge-efl.org/support/dloads/ket/KET_HB_intro.pdf

van Ek, J. A., \& Trim, J. L. M. (1991). Waystage 1990. France: Council of Europe. 
Wada, M. (2002). Speaking nouryoku no hyouka no kihon [Fundamentals of speaking ability assessment]. STEP the Latest on English, 4, 36-41.

Appendix: Evaluation Criteria

(a) Task Achievement (Tasks 2(1)-2(5), 3(1)-3(3); assessed item by item): e.g., Task 2(1)

\begin{tabular}{|c|c|c|c|}
\hline $\begin{array}{l}\text { Relevant to } \\
\text { the task } \\
\text { [Relevance] }\end{array}$ & $\begin{array}{l}\text { Said all key phrases (e.g., } \\
\text { Maruya, book, want to buy, [or } \\
\text { be going to buy]). NO major } \\
\text { errors }{ }^{1} \text { existed. }\end{array}$ & $\begin{array}{l}\text { There were unnatural pauses and } \\
\text { dysfluency markers (i.e., } \\
\text { repetitions, self-corrections, \& } \\
\text { false-starts). }\end{array}$ & $R$ \\
\hline \multirow[t]{3}{*}{$\bar{O}$} & \multirow[t]{2}{*}{ for both } & $x$ & 3 \\
\hline & & O & 2 \\
\hline & $x$ & & 1 \\
\hline $\bar{x}$ & & & 0 \\
\hline
\end{tabular}

(b) Vocabulary volume (c) Accuracy ${ }^{2}$ (Vocabulary \& Grammar, including appropriateness to the context)

\begin{tabular}{|c|c|c|c|c|c|c|}
\hline \begin{tabular}{ll|} 
No. & of \\
pruned & \\
tokens & \\
\end{tabular} & $\mathrm{R}$ & $\begin{array}{l}\text { Rele- } \\
\text { vance }\end{array}$ & $\begin{array}{l}\text { No. of major errors per } \\
\text { AS-unit (Foster et al., } \\
\text { 2000). }\end{array}$ & $\begin{array}{lr}\text { No. of } & \text { minor } \\
\text { errors } & \text { per } \\
\text { AS-unit } & \\
\end{array}$ & $\mathrm{R}$ & $\begin{array}{l}\text { Note. R } \\
= \\
\text { Rating. }\end{array}$ \\
\hline $60-$ & 3 & 0 & $0.00-0.32$ & $0.00-0.99$ & 3 & (b), (c), \\
\hline $30-59$ & 2 & & & $1.00-$ & 2 & \& $\quad$ (d) \\
\hline $1-29$ & 1 & & $0.33-$ & & 1 & are for \\
\hline 0 & 0 & $x$ & & & 0 & $\begin{array}{l}\text { Tasks } \\
1,4, \& \\
5 .\end{array}$ \\
\hline
\end{tabular}

(d) Fluency: The lowest rating among the three aspects becomes the final rating.

\begin{tabular}{|c|c|c|c|c|c|}
\hline $\begin{array}{l}\text { Rele- } \\
\text { vance }\end{array}$ & $\begin{array}{l}\text { (1) Speech rate: } \\
\text { No. of pruned } \\
\text { words per } \\
\text { minute }\end{array}$ & $\begin{array}{ll}(2) \quad \text { No. of } \\
\text { disfluency } \\
\text { markers } \\
\text { minute }\end{array}$ & $\begin{array}{l}\text { (3) No. of filled } \\
\text { and unfilled } \\
\text { pauses } \\
\text { minute }\end{array}$ & $\mathrm{R}$ & $\begin{array}{l}\text { Note. The } \\
\text { category of } \\
\text { pronunciation } \\
\text { was excluded for }\end{array}$ \\
\hline \multirow[t]{3}{*}{$\bar{O}$} & $40.00-$ & $0.00-19.99$ & $000-19.99$ & 3 & \multirow{4}{*}{$\begin{array}{l}\text { a lack of } \\
\text { reliability. } \\
{ }^{1} \text { Major errors are } \\
\text { the ones that } \\
\text { interfere with } \\
\text { understanding. }\end{array}$} \\
\hline & $20.00-39.99$ & $20.00-39.99$ & $20.00-39.99$ & 2 & \\
\hline & $0.00-19.99$ & 40.00 & $40.00-$ & 1 & \\
\hline$x$ & & & & 0 & \\
\hline
\end{tabular}

